\title{
EFEITO DA SALINIDADE NA GERMINAÇÃO DE SEMENTES E NO CRESCIMENTO INICIAL DE MUDAS DE PINHÃO-MANSO ${ }^{1}$
}

\author{
YARA ANDRÉO-SOUZA ${ }^{2}$, ARMANDO LOPES PEREIRA ${ }^{3}$, FABRÍCIO FRANCISCO SANTOS DA SILVA 4 , \\ RENATA CONDURU RIEBEIRO-REIS ${ }^{5}$, MÁRCIO RANNIERI VIANA EVANGELISTA ${ }^{6}$, \\ RENATO DELMONDEZ DE CASTRO ${ }^{7}$, BÁRBARA FRANÇA DANTAS ${ }^{8}$
}

\begin{abstract}
RESUMO - O pinhão-manso (Jatropha curcas L.) é encontrado em quase todas as regiões intertropicais do planeta, sendo adaptável a condições edafoclimáticas da região Nordeste até São Paulo e Paraná. Objetivou-se através do presente trabalho avaliar o comportamento de sementes e mudas de pinhão-manso quando submetidas à condição de estresse salino. Para isso foram conduzidos dois experimentos, sendo o primeiro realizado em condições de laboratório e o segundo em campo. Para o primeiro experimento as sementes de pinhão-manso, dos dois lotes foram submetidas a diferentes concentrações de cloreto de sódio, obtidas da dissolução de cloreto de sódio em água destilada, obtendo as condutividades elétricas de 2, 4, 6, 8, 10, 12, dS.m ${ }^{-1}$, constituindo os tratamentos. No experimento II as mudas foram obtidas através da semeadura em vaso, e foram utilizados como tratamentos as concentrações 2, 4, e $6 \mathrm{dS} . \mathrm{m}^{-1}$; como controle foi utilizado água destilada para os dois experimento. Sementes de pinhão-manso sofrem atraso no processo germinativo, devido a condições de salinidade. Há redução no crescimento das plântulas quando submetidas à solução de $\mathrm{NaCl}$ com condutividade elétrica de $6 \mathrm{dS} \cdot \mathrm{m}^{-1}$. Dessa forma, a condição de estresse salino interfere nos processos fisiológicos das sementes de pinhão-manso.
\end{abstract}

Termos para indexação: lotes, qualidade fisiológica, crescimento, desenvolvimento, estresse salino.

\section{EFFECT OF SALINITY ON PHYSIC NUT (JATROPHA CURCAS L.) SEED GERMINATION AND SEEDLING INITIAL GROWTH}

\begin{abstract}
The physic nut (jatropha curcas 1.) Shrub is found in almost all the intertropical regions, and is adaptable to climatic conditions from the brazilian northeast to são paulo and paraná. We evaluated the effects of salt stress on $j$. Curcas seeds and seedlings grown under laboratory and field conditions. In the laboratory experiments, two lots of physic nut seeds were submitted to different concentrations of sodium chloride dissolved in distilled water to produce electrical conductivities $\left(\mathrm{ds} \mathrm{m}^{-1}\right)$ of $2,4,6,8,10$ and 12. For the field experiments, plants were grown in pots watered with sodium chloride dissolved in distilled water to produce electrical conductivities of $2 \mathrm{ds} \mathrm{m}^{-1}, 4 \mathrm{ds} \mathrm{m}^{-1}$ and $6 \mathrm{ds} \mathrm{m}^{-1}$. A distilled water control was used for both sets of experiments. Our results indicate that $j$. Curcas seeds suffer a
\end{abstract}

\footnotetext{
${ }^{1}$ Submetido em 22/07/2009. Aceito para publicação em 06/01/2010.

${ }^{2}$ Bióloga, Pesquisadora Bolsista Desenvolvimento Científico Regional, FACEPECNPq, Embrapa Semiárido. Laboratório de Análise de Sementes, CP.23, CEP: 56302-970, Petrolina, PE. email: yara andreo@yahoo.com. br.

${ }^{3}$ Biólogo, Mestrando. Embrapa Semiárido. Laboratório de Análise de Sementes, CP. 23, CEP: 56302-970, Petrolina, PE, email: armando. lopes@bol.com.br.

${ }^{4}$ Biólogo, Mestrando. Embrapa Semiárido. Laboratório de Análise de Sementes, CP. 23, CEP: 56302-970, Petrolina, PE, email: fabriciofrancisco2005@hotmail.com.
}

${ }^{5}$ Bióloga, Doutoranda Universidade Estadual de Feira de Santana, UEFS, Feira de Santana, BA, CEP: 44036-900, email: rconduru@gmail.com.

${ }^{6}$ Eng. Agr., Bolsista de Desenvolvimento Tecnológico Industrial - $\mathrm{CNPq}$, Embrapa Semiárido. Setor Floresta. CP. 23, CEP: 56302-970, Petrolina, PE, email: marcio.rannieri@cpatsa.embrapa.br.

${ }^{7}$ Eng. Agr., Professor Adjunto, Universidade Federal da Bahia, UFBA, CEP: 40170-115, Salvador, BA, email: rdelmondez@gmail.com.

${ }^{8}$ Eng. Agr.., Pesquisadora, Embrapa Semiárido. Laboratório de Análise de Sementes, CP. 23, CEP: 56302-970, email: bárbara@cpatsa.embrapa.br. 
delay in germination under saline conditions and that reduced seedling growth and development occur when they are subjected to sodium chloride solution with an electrical conductivity of $6 \mathrm{ds} \mathrm{m}^{-1}$. It thus appears that salt stress interferes with the physiological processes occurring in jatropha seeds.

Index Terms: lots, growth, development, physiological quality, stress.

\section{INTRODUÇÃO}

Pertencente à família das Euforbiáceas, a mesma da mamona e da mandioca, o pinhão-manso (Jatropha curcas L.), pode ser encontrado em quase todas as regiões intertropicais do planeta, estendendo sua ocorrência à América Central, Índia e Filipinas. No Brasil, é encontrado da região Nordeste até os estados de São Paulo e Paraná, com distribuição vasta devido à sua rusticidade e fácil adaptação a diferentes condições edafoclimáticas (Cortesão, 1956; Peixoto, 1973; Brasil, 1985).

Por ser uma espécie exigente em insolação e com forte resistência à seca, o pinhão-manso tem sido considerado como uma opção agrícola para a região nordeste, sendo muito bem adaptado às condições áridas e semiáridas. A maioria das espécies de Jatropha ocorre em áreas secas do cerrado e vegetação da caatinga (Deghan e Schutzman, 1994).

Segundo Carnielli (2003), é uma planta oleaginosa viável para a obtenção do biodiesel, pois apresenta alto rendimento em óleo. No Brasil, a exploração comercial dessa espécie ainda é incipiente e, até janeiro de 2008, era proibida a produção e a comercialização de sementes para a produção de biodiesel (Menani, 2008).

Para Purcino e Drummond (1986), a cultura do pinhãomanso pode se desenvolver nas pequenas propriedades, com a mão-de-obra familiar disponível, como acontece com a cultura da mamona, na Bahia, sendo mais uma fonte de renda para as propriedades rurais da Região Nordeste. Além disso, como é uma cultura perene, e segundo Peixoto (1973), pode ser importante para a conservação do solo, pois o cobre com uma camada de matéria seca, reduzindo, dessa forma, a erosão e a perda de água por evaporação, evitando enxurradas e enriquecendo o solo com matéria orgânica decomposta.

Apesar da grande demanda por informações sobre o pinhão-manso, os trabalhos de pesquisa se encontram em fase inicial. Ainda não há material selecionado, sistema de produção e zoneamento agrícola definidos; pouco se sabe do real potencial da planta. Assim, existe uma importante demanda por pesquisas na área de tecnologia de sementes e de produção de mudas.

A produção de mudas, em quantidade, é uma das etapas mais importantes no estabelecimento de povoamentos vegetais (Caldeira et al., 2000), e quando se produzem mudas pelo método sexuado o cuidado com a qualidade das sementes é indispensável. O baixo vigor das sementes eleva os custos de produção, pois aumenta a quantidade a ser utilizada, além de diminuir o vigor das mudas (Jesus, 1997).

Para que as sementes germinem é necessário que existam condições favoráveis de luz, temperatura e disponibilidade de água (Carvalho e Nakagawa, 2000). Mas, nem sempre essas condições são adequadas, especialmente em solos salinos e sódicos. Normalmente, solos afetados por sais são encontrados em zonas áridas e semiáridas, onde a evaporação é superior à precipitação ocasionando assim, o acúmulo de sais solúveis e o incremento do sódio trocável na superfície dos solos (Barros et al., 2004).

A área de insuficiência hídrica do Nordeste brasileiro abrange uma superfície de 150 milhões de hectares. Nessa região, a maioria dos perímetros de irrigação apresenta solos com alto teor de salinidade, que provocam desde a diminuição nos rendimentos das culturas até o abandono das áreas exploradas. Em Pernambuco, aproximadamente $20 \%$ da área total dos perímetros irrigados encontram-se com problemas de salinidade (Barros et al., 2004).

A alta concentração de sais é um fator de estresse para as plantas, pois reduz o potencial osmótico e proporciona a ação dos íons sobre o protoplasma. A água é osmoticamente retida na solução salina, de forma que o aumento da concentração de sais a torna cada vez menos disponível para as plantas (Ribeiro et al., 2001). Assim, com o aumento da salinidade ocorre diminuição do potencial osmótico do solo, dificultando a absorção de água pelas raízes (Amorim et al., 2002; Lopes e Macedo, 2008).

As sementes também sofrem influência significativa da condição de salinidade dos solos. Oalto teor de sais, especialmente de cloreto de sódio $(\mathrm{NaCl})$, pode inibir a germinação devido a diminuição do potencial osmótico, ocasionando prejuízos as demais fases do processo (Lima et al., 2005)

Nas regiões áridas e semiáridas, o excesso de sais no solo tem limitado a produção agrícola. A salinidade, tanto dos solos como das águas, é uma das principais causas da queda de rendimento das culturas. Entretanto, os efeitos dependem, ainda, de outros fatores, como espécie, cultivar, estádio fenológico, tipos de sais, intensidade e duração do estresse salino, manejo cultural e da irrigação e condições edafoclimáticas (Tester e Davénport, 2003).

As atividades para produção de plantas oleaginosas poderiam possibilitar a utilização dessas áreas e certamente teriam reflexos diretos sobre a oferta de produtos de 
origem vegetal na região Nordeste, além de promoverem a recuperação dos solos degradados pela salinidade. Contudo, o sucesso desses plantios é dependente, entre outros fatores, do conhecimento do comportamento das sementes e da produção de mudas que sejam capazes de resistirem às condições adversas do meio (Santos et al., 2008). Assim, o objetivo do presente trabalho foi verificar o efeito do estresse salino na germinação de sementes e no crescimento inicial de mudas de pinhão-manso.

\section{MATERIAL E MÉTODOS}

Sementes de pinhão-manso provenientes de propriedades nas cidades de Arco Verde e Santa Maria da Boa Vista - PE foram cedidas ao Laboratório de Análise de Sementes da Embrapa Semiárido, Petrolina-PE e constituíram os lotes aqui denominados lote I e lote II, respectivamente para cada uma das localidades. Foram conduzidos dois experimentos, sendo um em condição de laboratório e outro em campo.

Inicialmente os lotes foram caracterizados quanto ao grau de umidade, realizado pelo método da estufa a $105^{\circ} \mathrm{C} \pm 3$, durante 24 horas, de acordo com as Regras para Análise de Sementes - RAS (Brasil, 1992), utilizando-se duas repetições de 10 sementes para cada lote. Os resultados foram expressos em porcentagem média (base úmida), sendo que o lote I apresentou $4 \%$ e o lote II $9 \%$ de umidade.

Experimento I - Estresse salino em sementes - foi conduzido em condição de laboratório, sendo as sementes de pinhão-manso submersas em diferentes soluções de cloreto de sódio $(\mathrm{NaCl})$. Para obtenção das soluções de $\mathrm{NaCl}$, seguiu-se a tabela proposta por Richards (1980), onde quantidades de sal foram diluídas em água destilada e, posteriormente, tiveram sua condutividade elétrica medida em condutivímetro "Digimed" modelo CD-21. Foram colocados $1 ; 2 ; 3,2 ; 4,4 ; 5,4 ; 6,6$ g. .1 $^{-1}$ de $\mathrm{NaCl}$, e obtiveram-se as leituras de $2 ; 4 ; 6 ; 8 ; 10 ; 12$ dS.m${ }^{1}$ de condutividade elétrica, as quais foram denominadas como tratamentos. Como controle dos tratamentos água destilada foi utilizada sem adição de sal.

As sementes de cada um dos lotes foram submetidas ao teste de germinação, em quatro repetições de 25 sementes. Para tanto, foram distribuídas sobre papel germitest, umedecido com cada uma das soluções salinas em 2,5 vezes o peso do papel seco (Brasil, 1992). Os rolos obtidos foram mantidos em incubadora B.O.D a $30{ }^{\circ} \mathrm{C}$ (Añez et al., 2005) sem luz. Foram feitas as seguintes avaliações: primeira contagem de germinação (PC) que se constituiu da porcentagem de plântulas normais obtidas aos quatros dias após a semeadura; germinação final (GF), representada pela porcentagem de plântulas normais aos 14 dias; índice de velocidade de germinação (IVG) e tempo médio de germinação (TMG), calculados de acordo com as fórmulas descritas por Maguire (1962) e Labouriau (1983).
Com base nos resultados obtidos nesse primeiro experimento, foram escolhidas três concentrações de $\mathrm{NaCl}$, de condutividade elétrica conhecida, que constituíram os tratamentos utilizados no experimento II.

Experimento II - Estresse salino e desenvolvimento de mudas - para realização desse experimento, foram semeadas duas sementes de pinhão-manso em cada vaso plástico de capacidade de $10 \mathrm{~L}$, contendo como substrato solo de caatinga, obtido da área experimental pertencente à Embrapa Semiárido, e areia na proporção de 1:1, perfazendo um total de seis repetições para cada tratamento.

As concentrações de sal utilizadas foram 2, 4 e 6 dS.m 1 , obtidas da mesma forma que no experimento I, sendo o controle água destilada pura. A salinização do solo foi realizada colocando-se os vasos de cada tratamento em caixa d'água com capacidade de $500 \mathrm{~L}$, até que a água em excesso percolasse. Feito isso, as sementes foram semeadas, a uma profundidade de três centímetros, e os vasos colocados sobre bancada em casa de vegetação. As regas foram realizadas diariamente ou de acordo com a necessidade das plantas, com água de torneira.

Após 21 dias da instalação do experimento, foram avaliados os seguintes parâmetros, para apenas uma das plantas: altura da planta $(\mathrm{cm})$, número de folhas, comprimento da raiz $(\mathrm{cm})$, diâmetro do caule $(\mathrm{mm})$, índice relativo de clorofila (unidade SPAD), área foliar $\left(\mathrm{cm}^{2}\right)$, massa fresca e seca $(\mathrm{g}) \mathrm{de}$ caules + pecíolos; folhas e raízes. A área foliar das plântulas foi determinada por meio do medidor portátil (modelo Licor Li3100) e o índice relativo de clorofila foi avaliado após quatro leituras no clorofilômetro Spad-502 (Minolta Corp.) em quatro folhas distintas da mesma planta.

Foi adotado delineamento experimental inteiramente casualizado para condução dos testes e esquema fatorial $2 \times 7$ e $2 \times 5$, respectivamente, para os experimentos I e II, onde 2 são os lotes e 7 ou 5 são as concentrações de $\mathrm{NaCl}$. Os dados foram submetidos à análise de variância e a comparação de médias foi obtida pela aplicação do teste de Tukey, para o experimento II, ou Scott-Knott, para experimento I, ambos a 5\% de probabilidade. Os dados de primeira contagem foram transformados em $\sqrt{x}+0,5$ e os dados de germinação em $\sqrt{ } \mathrm{x} / 100$. Os cálculos estatísticos foram realizados no programa Sisvar (Ferreira, 2000).

\section{RESULTADOS E DISCUSSÃO}

Os dados obtidos no teste de germinação (Figura 1) indicam que os lotes de sementes de pinhão-manso (Jatropha curcas) apresentaram diferença significativa para todos os parâmetros avaliados. As sementes do lote I germinaram em menos tempo (TMG, Figura 1D), ou seja, o tempo, em dias, foi menor para que as sementes conseguissem iniciar o processo 
germinativo. O maior índice de velocidade de germinação (IVG, Figura 1C) foi verificado em sementes do lote II, assim como maior percentagem de sementes germinadas na primeira contagem (PC, Figura 1A) e na germinação final (GF, Figura 1B).
$\mathbf{A}$

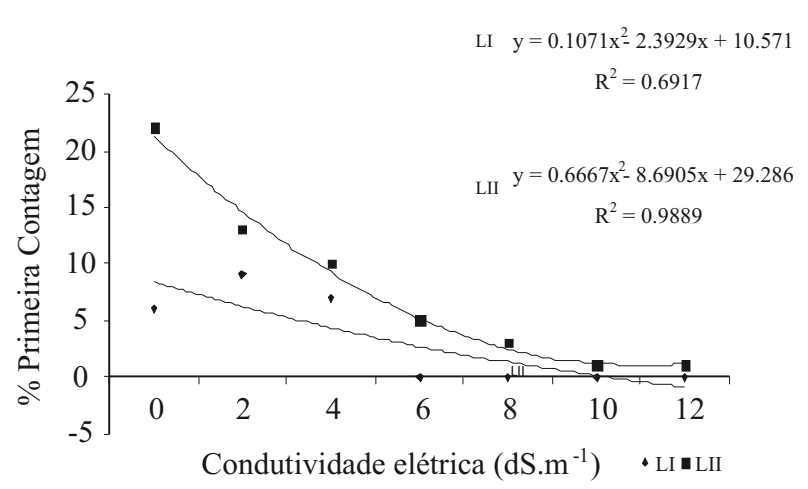

C

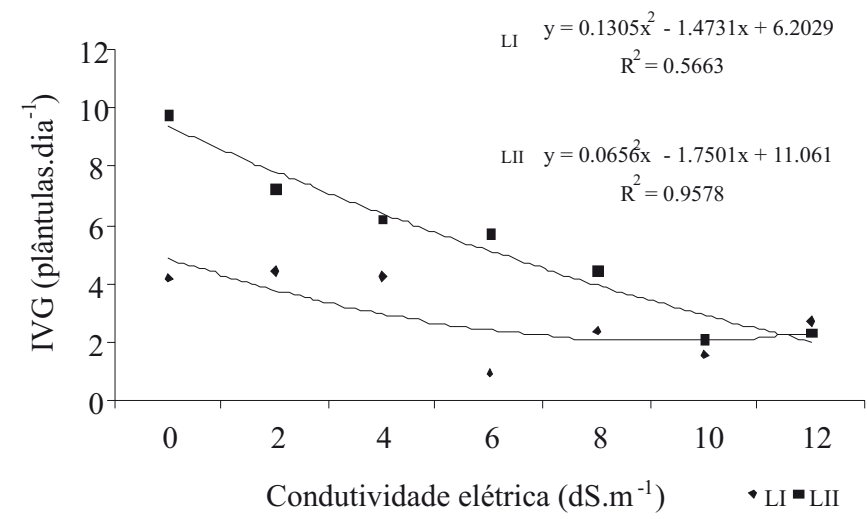

B

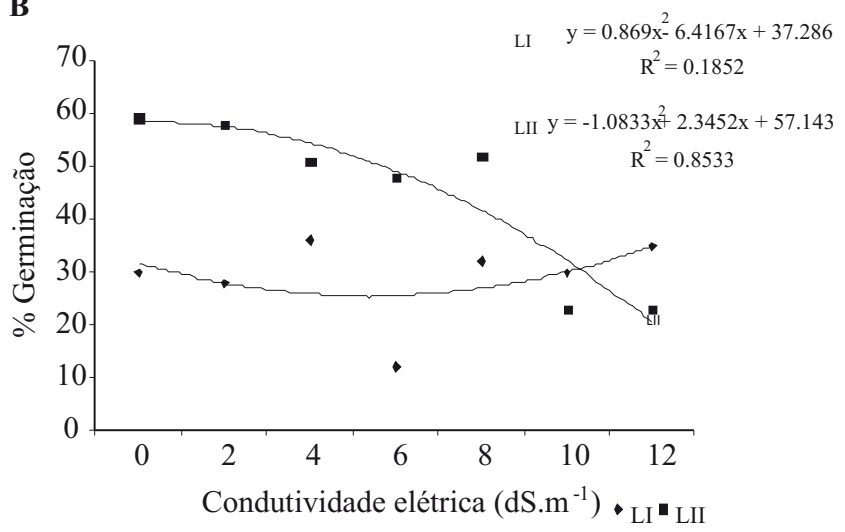

D

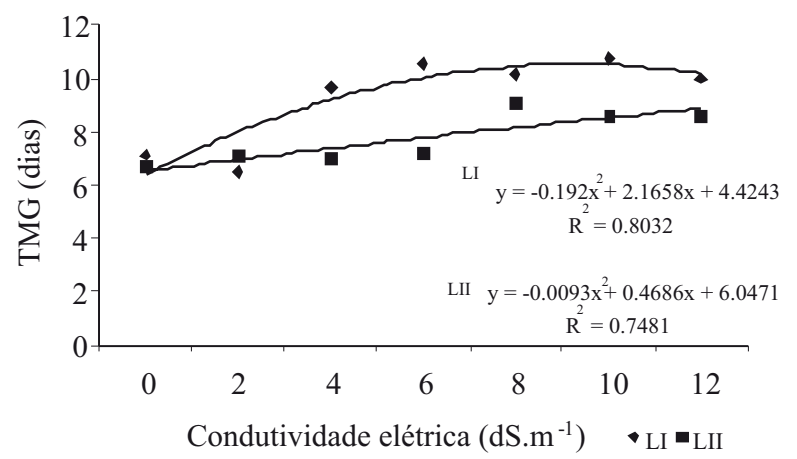

FIGURA 1. Primeira contagem de germinação (PC - A), germinação (TG - B), índice de velocidade de germinação (IVG - C) e tempo médio de germinação (TMG - D) de sementes de pinhãomanso (Jatropha curcas), lotes I e II, submetidas à soluções salinas com diferentes condutividades elétricas.

Comparando o efeito do estresse salino nos dois lotes, observou-se, em geral, melhor desempenho das sementes do lote II em relação ao lote I. No TMG as sementes do lote I germinaram em menor tempo no controle e na condutividade elétrica de $2 \mathrm{dS} . \mathrm{m}^{-1}$, enquanto que nas demais condições o lote II foi sempre superior (Figura 1D). O IVG sofreu redução significativa a partir de $6 \mathrm{dS} \cdot \mathrm{m}^{-1}$ para o lote I, enquanto que para o lote II as maiores reduções foram observadas em 10 e $12 \mathrm{dS}^{-1}$ (Figura $1 \mathrm{C}$ ).

As avaliações de PC e GF também foram influenciadas pela condição de estresse salino (respectivamente, Figuras $1 \mathrm{~A}$ e 1B). As sementes do lote I iniciaram o processo germinativo (PC) nas condições de baixa concentração de sal, enquanto as sementes do lote II germinaram em todos os tratamentos e apresentaram uma significativa redução nas concentrações de 10 e $12 \mathrm{dS} . \mathrm{m}^{-1}$.

No lote I os maiores prejuízos na germinação foram verificados na condição de $6 \mathrm{dS} \cdot \mathrm{m}^{-1}$, enquanto que no lote II as condições de 10 e $12 \mathrm{dS} \cdot \mathrm{m}^{-1}$ foram novamente os tratamentos mais prejudiciais, contudo as sementes germinaram nos diferentes tratamentos. Pizarro (1996), afirmou que condutividades elétricas do solo superiores a $2 \mathrm{dS} . \mathrm{m}^{-1}$ podem ocasionar danos à produção de cultivares sensíveis.

Torres (2007) observou que o efeito deletério do excesso de sal causa redução significativa da germinação para sementes de melancia (Citrullus lanatus Schrad.), a partir da condutividade de $11,2 \mathrm{dS} \cdot \mathrm{m}^{-1}$, sendo que 
os maiores prejuízos foram observados em elevadas condutividades, como 22,3 dS. $\mathrm{m}^{-1}$. Quando comparados os resultados da primeira contagem com os da percentagem final de germinação, os dados de primeira contagem foram os mais afetados com o aumento da condutividade elétrica dos tratamentos, este fato é esperado porque a velocidade de germinação é o primeiro parâmetro afetado pela redução da disponibilidade de água.

$\mathrm{O}$ aumento da concentração de sais no substrato determina redução no potencial hídrico, resultando em menor capacidade de absorção de água pelas sementes, o que geralmente influência a capacidade germinativa e o desenvolvimento das plântulas (Rebouças et al., 1989). A presença de níveis mais elevados de íons em plantas não halófitas (menos tolerantes à deficiência hídrica), pode exercer efeitos adversos na permeabilidade das membranas celulares (Greenway e Munns, 1980); ocasionando assim redução do processo germinativo em condições de níveis elevados de estresse salino, ressaltando que esses níveis são variáveis com a espécie.

Os dados de crescimento e desenvolvimento das plântulas de pinhão-manso (Figuras 2, 3 e 4) apresentaram diferença significativa para alguns parâmetros quando comparados os lotes. De forma geral, as plântulas obtidas de sementes do lote II apresentaram maior incremento no crescimento do que as plântulas do lote I. Na condutividade elétrica de $4 \mathrm{dS} \cdot \mathrm{m}^{-1}$ houve maior desenvolvimento das plantas em altura e de forma similar; também o comprimento das raízes das plântulas do lote II foi maior nessa condição (respectivamente, Figuras $2 \mathrm{~A}$ e $2 \mathrm{~B}$ ). O maior nível de estresse, $6 \mathrm{dS} . \mathrm{m}^{-1}$, afetou o crescimento e desenvolvimento das plantas dos dois lotes.
A

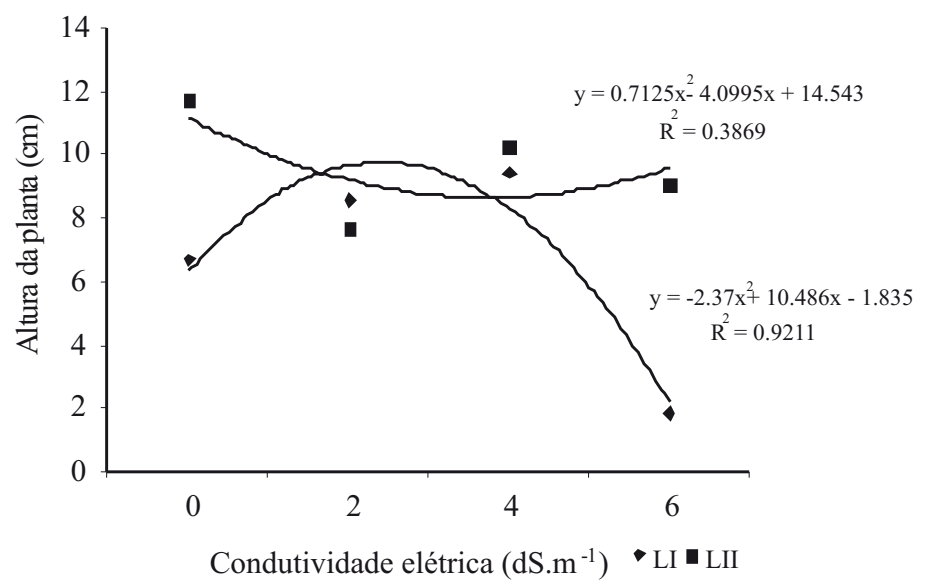

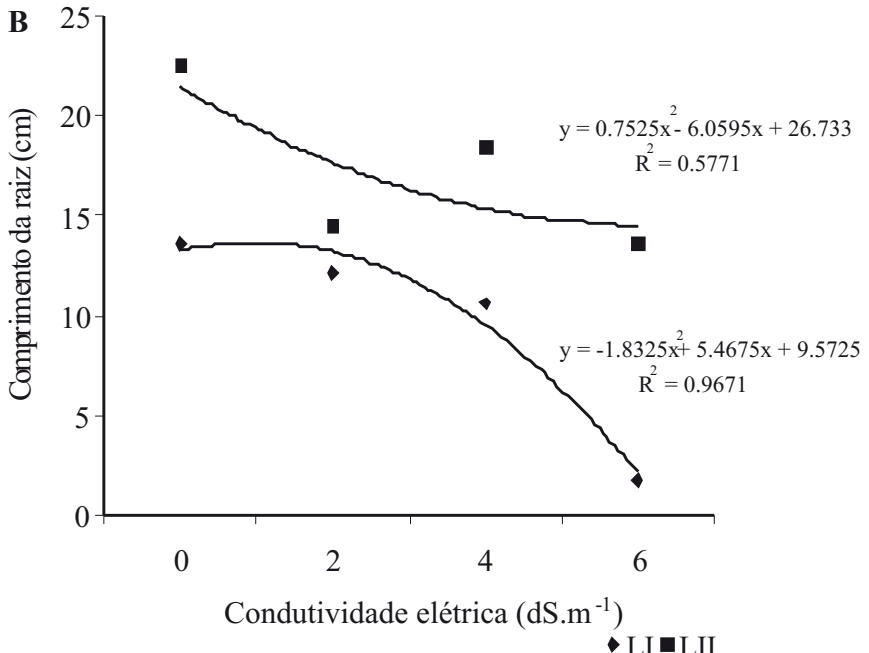

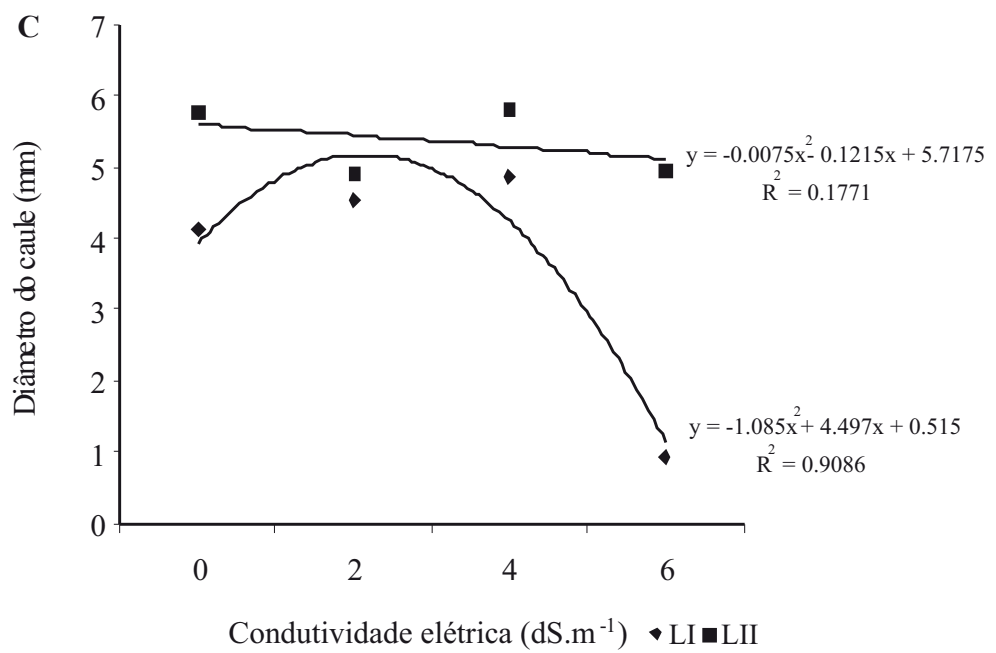

FIGURA 2. Crescimento de plântulas de pinhão-manso (Jatropha curcas): altura da planta (A), comprimento da raiz $(B)$ e diâmetro do caule $(C)$ de plântulas submetidas à soluções salinas com diferentes condutividades elétricas. 
A

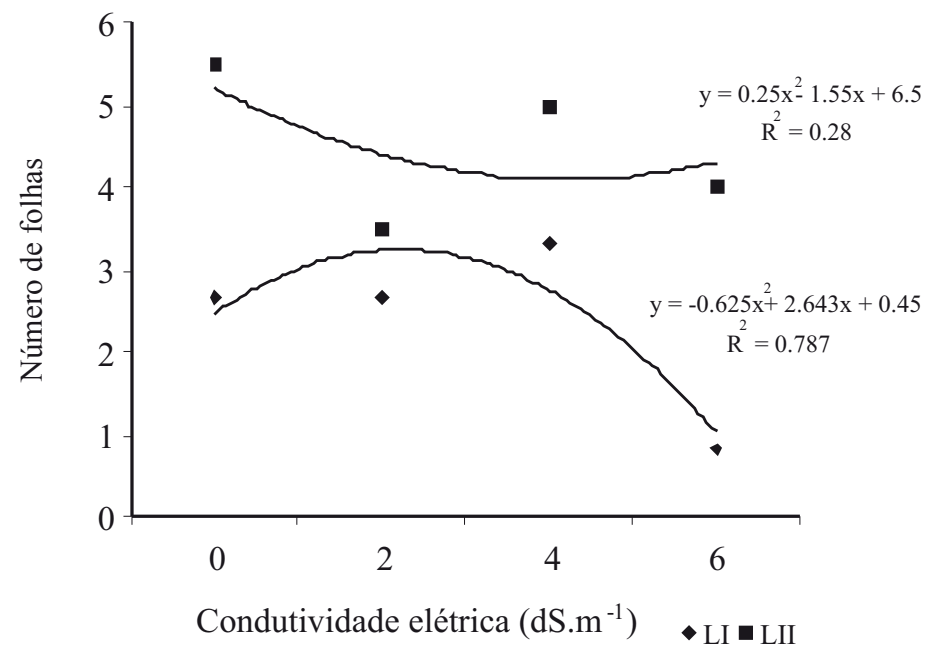

B

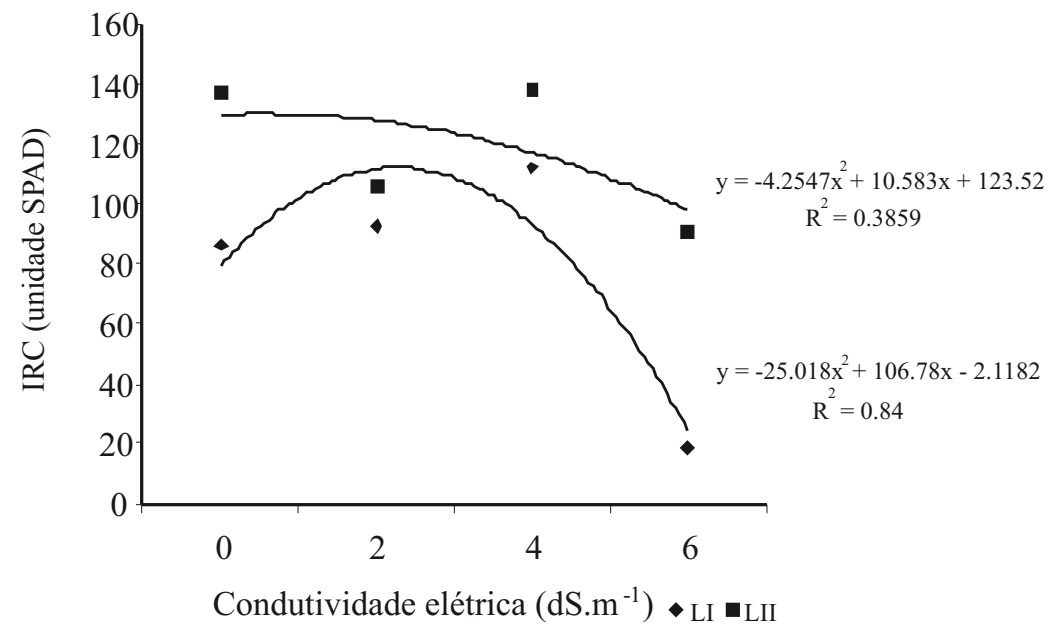

C

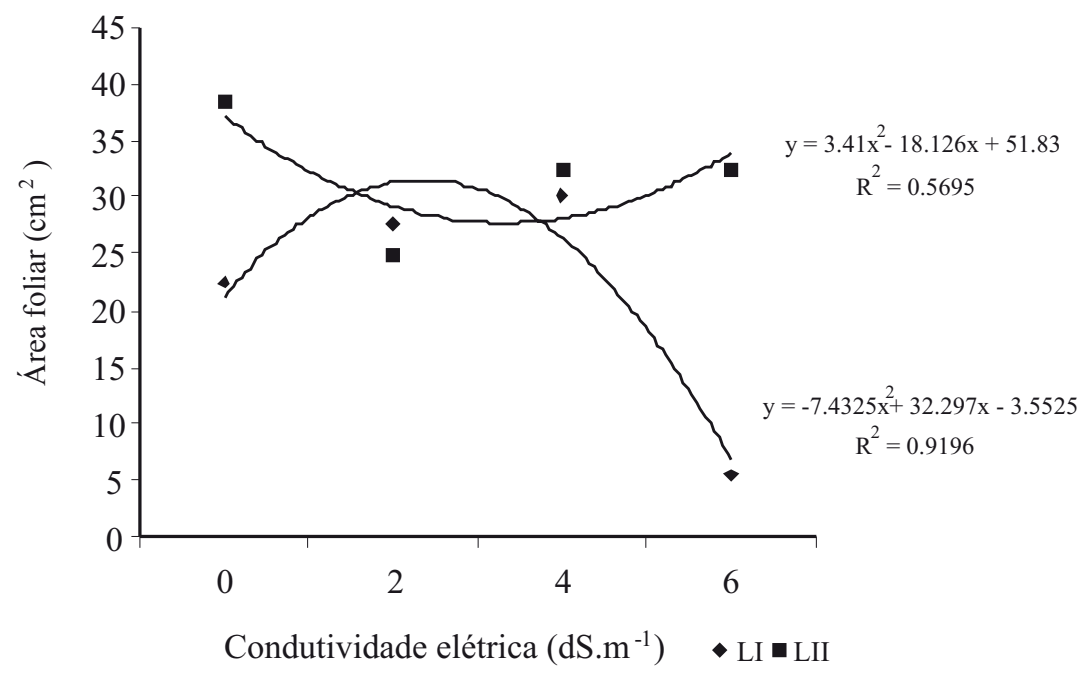

FIGURA 3. Crescimento e desenvolvimento de plântulas de pinhão-manso (Jatropha curcas): número de folhas, área foliar e índice relativo de clorofila (IRC) de plântulas submetidas à soluções salinas com diferentes condutividades elétricas. 
A
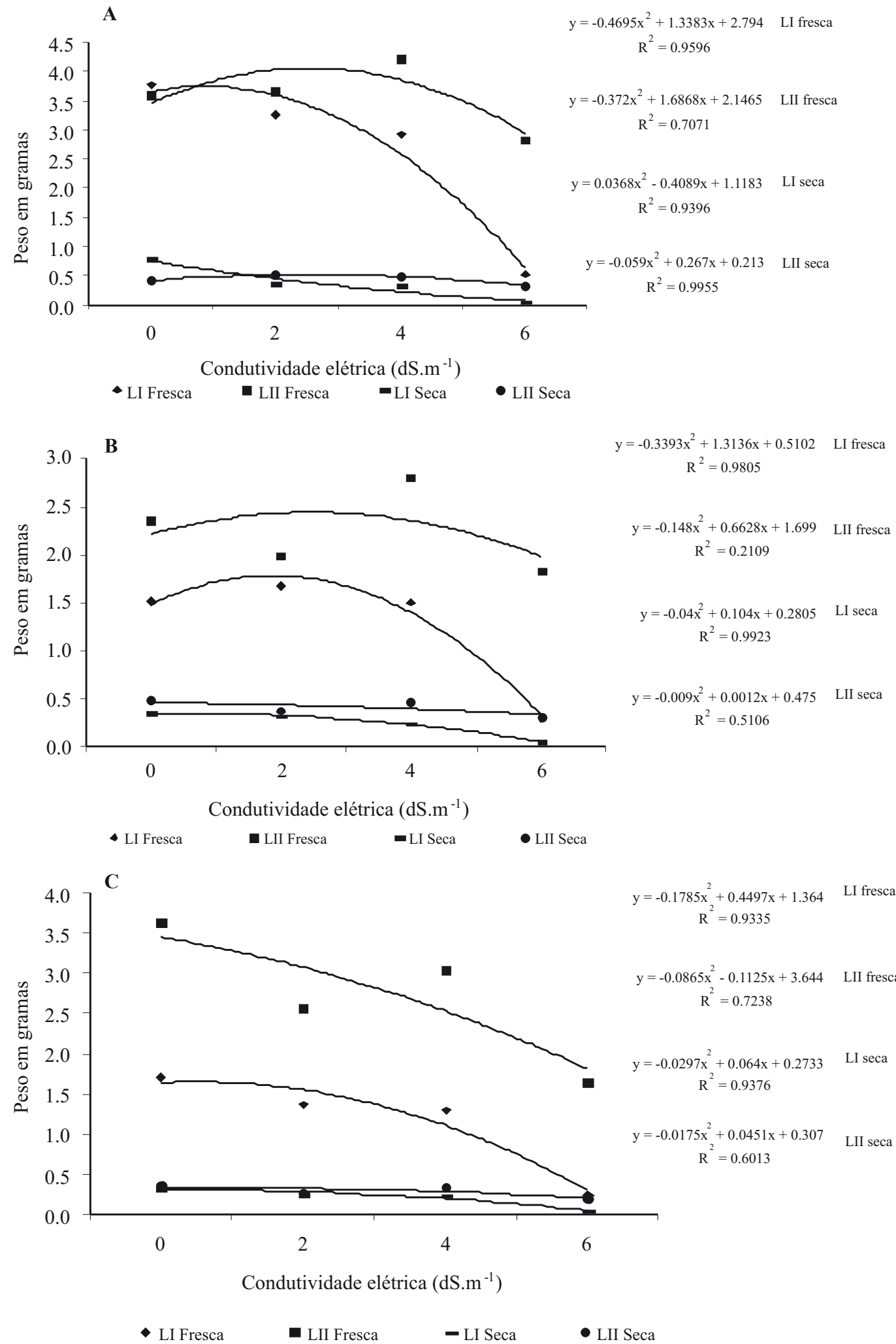

FIGURA 4. Peso das massas fresca e seca de plântulas de pinhão-manso (Jatropha curcas) submetidas à soluções salinas com diferentes condutividades elétricas: caule + pecíolo (A), folhas (B) e raízes (C). 
O diâmetro do caule (Figura 2C) das plântulas dos dois lotes de pinhão-manso foi superior na condição de 4 $\mathrm{dS} \cdot \mathrm{m}^{-1}$ e as massas de caule + pecíolo indicam um melhor desenvolvimento (Figura 4A) em relação as demais partes da planta (Figuras 4B e 4C). O número de folhas e suas massas não foram afetados pelas diferentes condutividades elétricas, havendo formação e desenvolvimento nas diferentes condições (Figuras 3 e 4B).

Em plantas de café (Coffea arabica L.) o diâmetro do caule foi influenciado pela salinidade da água ao longo do tempo, a partir de $1,2 \mathrm{dS} . \mathrm{m}^{-1}$, levando a paralisação do crescimento e consequentemente à morte (Figueiredo et al., 2006). Já mudas de catingueira (Caesalpinia pyramidalis Tul) submetidas à condutividade elétrica de $2 \mathrm{dS} . \mathrm{m}^{-1}$ apresentaram maior desenvolvimento para os parâmetros de altura, diâmetro do caule e número de folhas (Lopes et al., 2007).

Os diferentes tratamentos também não afetaram o índice relativo de clorofila (IRC, Figura 3B), sendo esse índice utilizado como indicativo de deficiência nutricional em plantas cultivadas, como para cafeeiro (Godoy et al., 2008) ou como indicativas de possíveis alterações no conteúdo de clorofila, ou seja, no pigmento fotossintético, ocasionando problemas na fotoassimilação e consequentemente no desenvolvimento e crescimento das plantas. Em plântulas de melão (Cucumis melo L.) submetidas a estresse salino foi constatada redução do IRC para diferentes cultivares, de acordo com o aumento da salinidade do solo (Aragão et al., 2009).

Quanto à área foliar (Figura $3 \mathrm{C}$ ), observou-se maior expansão das folhas na condutividade elétrica de $4 \mathrm{dS} . \mathrm{m}^{-1}$, indicando, mais uma vez, certa tolerância a essa condição pelas plântulas de pinhão-manso. Chartzoulakis (1994), irrigando o pepino (Cucumis sativus L.) com águas de diferentes salinidades verificou que a área foliar total das plantas reduziu quando se utilizou água de irrigação acima de $2,7 \mathrm{dS} \cdot \mathrm{m}^{-1}$, e que salinidades acima de 5,0 dS.m ${ }^{-1}$, proporcionaram efeitos ainda melhores na expansão foliar do que com propriamente no número de folhas.

De forma geral, a biomassa das diferentes partes da planta (Figuras 4A, B e C) indica um crescimento e desenvolvimento proporcional de suas partes, ou seja, caule+ pecíolo, folhas e raízes, além da uma possível tolerância ao estresse salino apresentado por essas plantas. Em arroz (Oryza sativa) a presença de cloreto de sódio não interferiu na massa das plântulas nos estágios iniciais de desenvolvimento, sendo que, normalmente, em plantas sensíveis à salinidade ocorre diminuição da taxa de emergência e redução nas matérias seca e fresca da parte aérea e do sistema radicular (Lima et al., 2005). Porém, Aragão et al. (2009) observaram redução na produção de matéria fresca e seca, nos teores de clorofila e de área foliar para diferentes cultivares de melão a partir da elevação da salinidade do solo, a partir de $2 \mathrm{dS} \cdot \mathrm{m}^{-1}$.

Torres (2007) também obsevou redução dos parâmetros de massa seca e comprimento para plântulas de melancia de acordo com o aumento da condutividade elétrica, dessa forma, efeitos adversos nas maiores concentrações desta solução na germinação e no desenvolvimento de plântulas.

Vale et al. (2006), estudando o estresse salino em mudas de pinhão-manso, afirmaram que as plantas irrigadas com água de condutividade elétrica de 0,06 e 4,2 dS.m ${ }^{-1}$, apresentaram redução da altura da planta, do diâmetro do caule, do número de folhas, sugerindo então, que as mesmas não podem ser cultivadas em solos salinos, assim os dados até aqui apresentados são conflitantes, uma vez que para as condições de estresse salino utilizadas no presente trabalho favoreceram o desenvolvimento inicial das plântulas de pinhão-manso.

\section{CONCLUSÃo}

Sementes de pinhão-manso sofrem atraso no processo germinativo, quando submetidas à condição de estresse salino na fase de embebição.

Há redução no crescimento das plântulas de pinhão-manso quando submetidas à solução de $\mathrm{NaCl}$ com condutividade elétrica de $6 \mathrm{dS} \cdot \mathrm{m}^{-1}$.

\section{AGRADECIMENTOS}

A primeira autora agradece ao $\mathrm{CNPq}$ pela bolsa de Desenvolvimento Científico Regional concedida e a FACEPE pelo auxílio ao projeto.

\section{REFERÊNCIAS}

AÑEZ, L.M.M.; COELHO, M.F.B.; ALBUQUERQUE, M.C.F.; DOMBROSKI, J.L.D. Caracterização morfológica dos frutos, das sementes e do desenvolvimento das plântulas de Jatropha elliptica Müll. Arg. (Euphorbiaceae). Revista Brasileira de Botânica, v.28, n.3, p.563-568, 2005.

AMORIM, J.R.A.; FERNANDES, P.D.; GHEYI, H.R.; AZEVEDO, N.C. Efeito da salinidade e modo de aplicação da água de irrigação no crescimento e produção de alho. Pesquisa Agropecuária Brasileira, v.37, n.2, p.167-176, 2002.

ARAGÃO, C.A.; SANTOS, J.J.; QUEIROZ, S.O.P.; DANTAS, B.F. Avaliação de cultivares de melão sob condições de estresse salino. Revista Caatinga, v.22, n.2, p.161-169, 2009. 
BARROS, M.F.C.; FONTES, M.P.F.; ALVAREZ, V.H.; RUIZ, H.A. Recuperação de solos afetados por sais pela aplicação de gesso de jazida e calcário no Nordeste do Brasil. Revista Brasileira de Engenharia Agrícola e Ambiental, v.8, n.1, p.59-64, 2004.

BRASIL. Ministério da Agricultura e Reforma Agrária. Secretaria Nacional de Defesa Agropecuária. Departamento Nacional de Defesa Vegetal. Coordenação de Laboratório Vegetal. Regras para análise de sementes. Brasília, DF, 1992. 365p.

BRASIL. Ministério da Indústria e do Comércio. Secretária de Tecnologia Industrial. Produção de combustíveis líquidos a partir de óleos vegetais. Brasília, DF: Secretaria de Tecnologia Industrial, 1985. 364p. (STI - CIT. Documentos, 16).

CALDEIRA, M.V.W.; SCHUMACHER, M.V.; TEDESCO, M. Crescimento de mudas de Acacia meamisii L. em função de diferentes doses de vermicomposto. Scientia Florestalis, n.57, p.161-170, 2000.

CARNIELLI, F. O combustível do futuro. 2003. Disponível em:<www.ufmg.br/boletim/bul1413>.

CARVALHO, N.M.; NAKAGAWA, J. Sementes: ciência, tecnologia e produção. 4.ed. Jaboticabal: FUNEP, 2000. $588 \mathrm{p}$.

CHARTZOULAKIS, K.S. Photosynthesis, water relations and leaf growth of cucumber exposed to salt stress. Scientia Horticulturae, v.59, p.27-35, 1994.

CORTESÃO, M. Culturas tropicais: plantas oleaginosas. Lisboa: Clássica, 1956. 231p.

DEGHAN, B.; SCHUTZMAN. B. Contributions towards a monograph of neotropical Jatropha: phonetic and phylogenetic analysis. Annals Missouri Botanica Garden, v.81, n.2, p.349-367, 1994.

FERREIRA, D.F. Análises estatísticas por meio do Sisvar para Windows versão 4.0. In: REUNIÃO ANUAL DA REGIÃO BRASILEIRA DA SOCIEDADE INTERNACIONAL DE BIOMETRIA, 45., 2000, São Carlos. Anais... UFSCar, São Carlos, SP, Julho de 2000. p.255-258.

FIGUEIREDO, V.B.; FARIA, M.A.; SILVA, E.L. Crescimento inicial do cafeeiro irrigado com água salina e salinização do solo. Revista Brasileira de Engenharia Agrícola e Ambiental, v.10, n.1, p.50-57, 2006.

GREENWAY, H.; MUNNS, R. Mechanisms of salt tolerance in nonhalophytes. Annual Review of Plant Physiology, v.31, p.149-190, 1980.

GODOY, L.J.G.; SANTOS, T.S.; VILLAS BOAS, R.L.; JÚNIOR, J.B.L. Índice relativo de clorofila e o estado nutricional em nitrogênio durante o ciclo do cafeeiro fertirrigado. Revista Brasileira de Ciências do Solo, v.32, p.217-226, 2008.

JESUS, B.M. Morfologia de sementes, germinação e desenvolvimento de mudas de angico de bezerro (Piitadenia oblqual (Pers.) Macbr.) Areia. 1997, 81f. (Dissertação de Mestrado). Universidade Federal da Paraíba.

LABOURIAU, L.G. A germinação das sementes. Washington, DC: OEA - Prog. Reg. Desenv. Cient. Tecnol., 1983. 174p. (Biologia, Monografia, 24).

LIMA, M.G.S.; LOPES, N.F.; MORAES, D.M.; ABREU, C.M. Qualidade fisiológica de sementes de arroz submetidas a estresse salino. Revista Brasileira de Sementes, v.27, n.1, p.54-61, 2005.

LOPES, J.C.; MACEDO, C.M.P. Germinação de sementes de sob influência do teor de substrato e estresse salino. Revista Brasileira de Sementes, v.30, n.3, p.79-85, 2008.

LOPES, A.; LUCIO, A.A.; SILVA, F.F.S.; SILVA, P.P.; DANTAS, B.F. Crescimento inicial de plântulas de catingueira (Caesalpinia pyramidalis Tul.) submetidas ao estresse salino. In: JORNADA DE CIENTÍFICA DA EMBRAPA SEMI-ÁRIDO - PIBIC - FACEPE/CNPq/EMBRAPA, 2, 2007, Petrolina. Anais... Petrolina: Embrapa Semi-Árido, 2007. (Embrapa Semi- Árido, 2007. (Embrapa Semi-Árido. Documentos, 205).

MAGUIRE, J.D. Speed of germination-aid in selection and evaluation of seedling emergence and vigour. Crop Science, v.2, n.1, p.176-177, 1962.

MENANI, R. Começa a corrida pelo pinhão-manso. Revista Biodiesel, v.3, n.25, p.20-22, 2008.

PEIXOTO, A.R. Plantas oleaginosas arbóreas. São Paulo: Nobel, 1973. 284p.

PIZARRO, F. Riegos Localizados de Alta Frecuencia. $3^{\text {a }}$ Edición. Madrid, España. Ediciones Mundi-Prensa. 1996, $511 \mathrm{p}$.

PURCINO, A.A.C.; DRUMMOND, O.A. Pinhão-manso. Belo Horizonte: EPAMIG, 1986. 7p.

REBOUÇAS, M.A.; FAÇANHA, J.G.V.; FERREIRA, L.G.R.; PRISCO, J.T. Crescimento e conteúdo de N, P, K e $\mathrm{Na}$ em três cultivares de algodão sob condições de estresse salino. Revista Brasileira de Fisiologia Vegetal, v.1, n.1, p.79-85, 1989.

RIBEIRO, M.C.C.; MARQUES, B.M.; AMARRO FILHO, J. Efeito da salinidade na germinação de sementes de quatro cultivares de girassol (Helianthus annuus L.). Revista Brasileira de Sementes, v.23, n.1, p.281-284, 2001.

RICHARDS, L.A. Suelos Salinos y Sodicos. Instituto Nacional de Investigaciones Agrícolas. México. 1980. 171p. 
SANTOS, H. O.; SILVA-MANN, R.; ANDRADE, T. M.; CORTEZ, P. C. C. F.; BISPO, M.V.C.; ROCHA, R. C.; CARVALHO, M. L. M. Potencial germinativo de sementes de mamona (Ricinus communis L.) submetidas a estresse salino. In: CONGRESSO BRASILEIRO DE MAMONA, 3., 2008, Salvador. Energia e ricinoquímica: Resumos. Salvador: SEAGRI: Embrapa Algodão, 2008.

TESTER, M.; DAVÉNPORT, R. Na+tolerance and $\mathrm{Na}+$ transport in higher plants. Annals of Botany, v.19, p.503527, 2003.
TORRES, S.B. Germinação e desenvolvimento de plântulas de melancia em função da salinidade. Revista Brasileira de Sementes, v.29, n.3, p.77-82, 2007.

VALE, L.S.; SEVERINO, L.S.; BELTRÃO, N.E. Efeito da salinidade da água sobre o pinhão-manso. In: CONGRESSO DA REDE BRASILEIRA DE BIODIESEL, 1., 2006, Brasília: DF. Anais... Brasília, DF: MCT/ABIPTIT, v.1, p.87-90, 2006. 